\title{
ENKELE WETENSWAARDIGHEDEN UIT DE ONTWIKKELINGSGESCHIEDENIS DER AMSTERDAM- SCHE COMBINATIE: ZOOLOGISCH LABORATORIUM, ZOOLOGISCH MUSEUM EN ZOOLOGISCHE TUIN
}

\author{
DOOR \\ DR. A. L. J. SUNIER \\ Directeur van het Koninklijk Zoölogisch Genootschap Natura Artis Magistra \\ te Amsterdam
}

De uitgave door het Koninklijk Zoölogisch Genootschap Natura Artis Magistra van een aflevering zijner Bijdragen tot de Dierkunde ter gelegenheid van het bereiken in 1949 van den 70-jarigen leeftijd door de huidige directeuren van het Zoölogisch Laboratorium en van het Zoölogisch Museum te Amsterdam, welke gemeentelijke instellingen beide gelegen zijn in den tuin van het Genootschap en gehuisvest zijn in gebouwen, die oorspronkelijk aan het Genootschap behoorden, is een ongezochte aanleiding eenige niet algemeen bekende feiten te memoreeren uit de ontwikkelingsgeschiedenis der Amsterdamsche combinatie: zoölogisch laboratorium; zoölogisch museum en zoölogische tuin.

Artikel I der eerste Wet van het Koninklijk Zoölogisch Genootschap Natura Artis Magistra, ,goedgekeurd en gearresteerd” den 20sten Maart I839, luidde: „Het doel van dit Genootschap is het bevorderen van de kennis der Natuurlijke Historie, op eene aangename en aanschouwelijke wijze; zoo door het bijeenbrengen eener uitgebreide verzameling van levende dieren, als door het plaatsen van een kabinet van opgezette voorwerpen uit het dierenrijk." 1 )

Het hier bedoelde kabinet van opgezette voorwerpen uit het dierenrijk is

1) Tegenwoordig luidt artikel I der Wet van het Genootschap als volgt :

„Het Genootschap werd op de Iste Mei I838 onder de spreuk Natura Artis Magistra gesticht met als doel het op een aangename en aanschouwelijke wijze bevorderen van de kennis der natuurlijke historie in het algemeen en der dierkunde in het bijzonder.

Als instelling zonder lucratief doel ziet het Genootschap het als zijn opvoedende taak om, door het instandhouden ener zo gevarieerd mogelijke verzameling levende dieren en het geven van voorlichting, belangstelling voor het levende dier te wekken en te onderhouden, terwijl het ook het dierkundig onderzoek, in de meest uitgebreide zin des woords, wil helpen bevorderen.

Daarnaast werkt het Genootschap mede aan de bescherming der wilde fauna van de gehele wereld." 
de kiem, van waaruit het Zoölogisch Museum te Amsterdam zich ontwikkeld heeft.

Het Zoölogisch Laboratorium der Gemeente-Universiteit van Amsterdam genoot gastvrijheid van het Genootschap sedert kort na 1877 .

Den 3osten October 1877 kwam n.l. een overeenkomst tusschen de Gemeente Amsterdam en het Genootschap tot stand, waarbij de Gemeente aan het Genootschap „schonk” en „om niet afstond” een stuk grond, groot $2735 \mathrm{~m}^{2}$, gelegen aan de N.O.-zijde en het Z.O.-lijk uiteinde van de Plantage Middenlaan, onder voorwaarde, dat de a fgestane grond niet anders zou mogen worden gebezigd dan tot oprichting en onderhoud van een aquarium met lokalen voor het onderwijs, van welk een en ander door de Gemeente ten behoeve van het universitaire onderwijs zou kunnen worden gebruik gemaakt, terwijl, indien te eeniger tijd de vermelde grond van bestemming mocht worden veranderd, deze van de daarop geplaatste opstallen ontdaan, weder kosteloos aan de Gemeente moest worden afgestaan en overgedragen.

Uit den aard der zaak is het practisch gesproken niet mogelijk, gezien de aan deze schenking verbonden voorwaarde; de waarde dier schenking ook maar bij benadering vast te stellen. Ter oriënteering in deze moge slechts dienen, dat in 1878 door de Gemeente de grond, gelegen aan de Plantage Middenlaan, tegenover het huidige aquarium, publiek in verschillende kavels verkocht werd tegen $f$ 45. - à $f$ o. - per $m^{2}$.

Hoewel voorts bovenbedoelde voorwaarde niet behelst, dat de Gemeente kosteloos van het aquarium en de lokalen voor het onderwijs gebruik zou kunnen maken, werd voor dit gebruik nimmer eenige vergoeding door het Genootschap aan de Gemeente gevraagd of van de Gemeente ontvangen.

Den I6den Mei I892 kwam een tweede zeer belangrijke overeenkomst tot stand tusschen de Gemeente en het Genootschap.

Daarbij werden in de eerste plaats de zoölogische museumverzamelingen van het Genootschap en van de Gemeente samengevoegd in de voor die collecties bestemde museumruimten van het Genootschap, terwijl de aldus samengevoegde verzamelingen kwamen te staan onder de wetenschappelijke leiding van den hoogleeraar in de zoölogie, tevens directeur van het sedert de overeenkomst van 1877 in het aquariumgebouw van het Genootschap gevestigde Zoölogisch en Zoötomisch Laboratorium der Gemeente-Universiteit.

Uitgezonderd wend hiervan slechts de insecten-collectie van het Genootschap, in verband met het feit, dat de Gemeente toentertijd geen noemenswaardig bezit op dit gebied had.

Tevens werd bepaald, dat de samengevoegde verzamelingen gesplitst zouden worden in ,show-collections" en ,wetenschappelijke verzamelingen in engeren zin". Wat de show-collectie betreft werden sedertdien door het Genootschap o.a. de bekende, fraaie, door den praeparateur P. L. Steenhuizen vervaardigde biologische groepen tot stand gebracht.

In de tweede plaats werd overeengekomen, dat door het Genootschap aan 
alle studenten, die als toehoorders bij den hoogleraar in de zoölogie ingeschreven zouden zijn, vrijen toegang tot alle inrichtingen en verzamelingen van het Genootschap verleend zou worden.

In de derde plaats verklaarde het Genootschap zich bereid in de toekomst alle in de diergaarde of in het aquarium gestorven dieren ter beschikking te stellen van het onderwijs in de zoölogie aan de Gemeente-Universiteit, mits de huiden, skeletten of schedels, of wel alle deze organen, indien dit verlangd werd, in ongeschonden staat aan het Genootschap werden teruggegeven.

Het tot stand komen van deze overeenkomst hield ongetwijfeld direct verband met de benoeming, in Juni $\mathbf{1} 890$, van Dr. C. KERBERT tot directeur van het Genootschap en met het feit, dat het Genootschap, blijk gevend van een breed inzicht, op zuiver ideëele overwegingen, er toe wilde bijdragen Prof. MAx WEBER, die sedert I884 gewoon hoogleeraar in de zoölogie en directeur van het zoölogisch laboratorium was, in de gelegenheid țe stellen zijn neiging te volgen en zijn zeer bijzondere gaven in het belang van de ontwikkeling van het zoö'ogisch museum aan te wenden.

Daar, toen Prof. Weber in I884 tot gewoon hoogleeraar benoemd werd, de Universiteit der Gemeente Amsterdam slechts over een verzameling van dierlijke voorwerpen beschikte, die, naar de woorden van Prof. Weber zelf, „niet eens den naam van „schoolmuseum” verdiende wegens haar desolaat en geheel onsamenhangend karakter", zal het duidelijk zijn van hoe groote beteekenis en ook van hoe groot materieel voordeel het voor de Gemeente was, om voor haar universitaire onderwijs de beschikking te krijgen over de uitgebreide verzamelingen van het Genootschap, alsmede over de ruimten, waarin deze verzamelingen gehuisvest waren.

Materieel voordeel van eenige beteekenis voor het Genootschap leverde de overeenkomst van I892 zeer zeker niet op.

De op zuiver ideëele overwegingen berustende geneigdheid van het Genootschap om, in het algemeen belang, het zoölogisch museum in samenwerking met de Gemeente tot grooter ontwikkeling te brengen, kwam zeer zeker ook tot uitdrukking in de benoeming, in I893, van Prof. Max Weber en later, in 1924, op aanbeveling van Prof. Weber, ook van diens opvolger aan het zoölogisch museum, Dr. L. F. DE BEAUfORT, die resp. als buitengewoon hoogleeraar, belast met de leiding der zoölogische verzamelingen en als directeur van het zoölogisch museum te Amsterdam, gemeente-ambtenaar waren, tot lid van het bestuur van het Genootschap.

Den r6den Mei I892 werd nog een tweede overeenkomst gesloten tusschen de Gemeente Amsterdam en het Genootschap, waarbij besloten werd tot een soortgelijke samenvoeging van de mineralogische, geologische en palaeontologische verzamelingen van de Gemeente en van het Genootschap als voor de zoölogische verzamelingen overeengekomen was.

Aan deze tweede overeenkomst werd echter slechts in den allereersten tijd, nadat $z$ ij gesloten was, een allereerste begin van uitvoering gegeven door den 
toenmaligen, daarbij betrokken hoogleeraar, Prof. G. A. F. MolengraAff. Den 2Isten Maart I925 wend deze overeenkomst door het Genootschap opgezegd.

Den 8sten December 1920 kwam wederom een nieuwe overeenkomst tot stand tusschen de Gemeente en het Genootschap, waarbij de overeenkomsten van 30 October 1877 en 16 Mei 1892 gewijzigd werden.

Aanleiding tot deze nieuwe overeenkomst was het feit, dat het Genootschap in I914, vóór het uitbreken van den eersten wereldoorlog, bij Burgemeester en Wethouders van Amsterdam aanhangig had gemaakt een plan tot stichting, in samenwerking tusschen de Gemeente en het Genootschap, van een groot nieuw zoölogisch museum voor de gecombineerde verzamelingen van de Gemeente en van het Genootschap. Voor de uitvoering van dit plan was o.a. noodig de beschikking, voor museumdoeleinden, over de lokalen in het aquariumgebouw, waarvan het Genootschap aan de Gemeente het gebruik had vergund, ten behoeve van het universitaire onderwijs, bij de overeenkomsten van 30 October I877 en I6 Mei I892. In verband hiermede had het Genootschap de Gemeente, voor de inrichting van een nieuw zoölogisch laboratorium, aangeboden het bovengedeelte van het gebouw De Volharding, dit is de ruimte boven de runderstallen in Artis, in welk bovengedeelte op dat tijdstip de ethnographische verzamelingen van het Genootschap ondergebracht waren.

Het uitbreken van den eersten wereldoorlog makte voorloopig voor beide partijen de uitvoering van het plan tot den bouw van een nieuw zoölogisch museum onmogelijk. Daar echter ondertusschen de beschikbare ruimte in het aquariumgebouw ook onvoldoende werd voor het zoölogisch onderwijs, werd in 1920 besloten, om, in afwachting van de hervatting der onderhandelingen over het plan tot den bouw van een nieuw zoölogisch museum, reeds dadelijk over te gaan tot het beschikbaar stellen van genoemd bovengedeelte in het gebouw De Volharding voor verbouwing en inrichting tot Zoölogisch Laboratorium van de Universiteit van Amsterdam, hetgeen dan werd vastgelegd in de overeenkomst van 8 December I920.

De wijzigingen, die daarbij de overeenkomsten van 1877 en 1892 ondergingen, kwamen in hoofdzaak op het volgende neer.

Wat den in 1877 door de Gemeente afgestanen grond van het aquariumgebouw betreft, werd bepaald, dat deze grond, zonder schriftelijke toestemming van Burgemeester en Wethouders niet anders mocht worden gebezigd dan voor de oprichting en instandhouding van een aquarium of voor musea of bibliotheek op natuur-historisch gebied, terwijl, indien hiervan werd afgeweken, het Genootschap niet alleen den bedoelden grond, maar ook al hetgeen dan daarop zou zijn gebouwd, kosteloos aan de Gemeente moest afstaan en overdragen, wanneer Burgemeester en Wethouders het verlangen daartoe schriftelijk te kennen gaven binnen drie maanden, nadat de veranderde bestemming te hunner kennis was gekomen. Ditzelfde zou gelden, indien het gebruik door de Gemeente voor zoölogisch laboratorium van het bovengedealte van het gebouw 
De Volharding mocht eindigen door opzegging of feitelijk beletten door het Genootschap, mits Burgemeester en Wethouders dezen kosteloozen afstand en overdracht schriftelijk vorderden binnen drie maanden na het eindigen van het gebruik.

Wat de overeenkomst van 1892 betreft, zoo werd de daarin voorkomende aanwijzing, voor het onderwijs in de zoölogie, van bepaalde ruimten in het aquariumgebouw vervangen door de aanwijzing daartoe van het genoemde bovengedeelte van het gebouw De Volharding.

Voorts verplichtte het Genootschap zich vrijen toegang te verleenen tot den tuin en alle inrichtingen en verzamelingen van het Genootschap aan alle professoren, lectoren, privaat-docenten, conservatoren, assistenten en studenten, die volgens de Verordening op de Universiteit van Amsterdam recht hadden werkzaam te zijn of colleges te volgen in het zoölogisch laboratorium.

Ten slotte werd overeengekomen, dat, indien het gebruik van het bovengedeelte van het gebouw De Volharding mocht eindigen door opzegging of feitelijk beletten daarvan door het Genootschap, dit aan de Gemeente zou hebben te vergoeden alle kosten, door de Gemeente gemaakt voor de verbouwing en inrichting (afgezien van tot de inrichting behoorende roerende zaken) van genoemd bovengedeelte, echter tot geen hooger bedrag dan $f 300.000$.-, welke vergoeding evenwel niet verschuldigd zou zijn, indien de Gemeente op grond van het beëindigen van bedoeld gebruik de bepaling inzake het kosteloos aan de Gemeente afstaan en overdragen van den grond van het aquariumgebouw en al hetgeen daarop gebouwd zou zijn, mocht hebben toegepast.

Dat ook deze overeenkomst van zeer groote, niet alleen ideëele maar ook materieele voordeelen voor de Gemeente was, spreekt wel van zelf. Hierbij moge er o.a. op gewezen worden, dat nimmer door het Genootschap een huursom aan de Gemeente gevraagd of van de Gemeente ontvangen werd voor het tot zoölogisch laboratorium verbouwd en ingericht bovengedeelte van het gebouw De Volharding, ook niet in den vorm van een jaarlijksche afschrijving op bovengenoemd bedrag van $f$ 300.000.-.

De zuiver ideëele beteekenis voor het Genootschap van de overeenkomst van I920 was gelegen in het daardoor scheppen van de mogelijkheid tot het mettertijd uitvoeren van bovengenoemde plannen tot den bouw van een nieuw zoölogisch museum, alsook in het tegemoet komen aan de eischen van het universitaire onderwijs in de zoölogie en in het daarmede verstevigen van den band, die tusschen de Universiteit van Amsterdam en het Genootschap bestond.

Met het tot stand komen der overeenkomst van 1920 hield voorts verband de afvoering van de terreinen van het Genootschap, in Augustus 1920, der ethnographische verzamelingen van het Genootschap, tot op dat tijdstip ondergebracht in het bovengedeelte van het gebouw De Volharding, welke verzamelingen den 7den November I921 door het Genootschap geschonken werden aan de Koninklijke Vereeniging Koloniaal Instituut, alhier.

In Maart 1923 werd het zoölogisch laboratorium in het bovengedeelte van 
het gebouw De Volhanding door het Genootschap aan de Gemeente Amsterdam overgedragen.

Ondertusschen hadden, met onderhandsch onderling goedvinden van de Gemeente en het Genootschap, eenige afwijkingen plaats van de overeenkomst van I6 Mei I892. Toen n.l. in I898 Prof. Dr. C. Ph. Sluiter tot gewoon hoogleeraar in de zoölogie en directeur van het zoölogisch laboratorium en Prof. MAX WeBer tot buitengewoon hoogleeraar benoemd werden, geschiedde dit laatste onder de bepaling, dat de buitengewoon hoogleeraar Prof. MAX WEBER belast werd met de leiding der zoölogische verzamelingen. Hiermede werd dus afgeweken van de bepaling in de overeenkomst van 16 Mei I892, luidende, dat de samengevoegde verzamelingen onder de wetenschappelijke leiding stonden van den hoogleeraar in de zoölogie, tevens directeur van het Zoölogisch en Zoötomisch Laboratorium der Gemeente-Universiteit.

Een verdere afwijking in deze richting van de overeenkomst van I6 Mei I 892 had plaats, toen, na het aftreden van Prof. MAx Weber, in 1922, Dr. L. F. De Beaufort, op voorstel van Prof. MAX Weber, welk voorstel, op verzoek van Prof. Weber, door het Genootschap ondersteund werd, door Burgemeester en Wethouders van Amsterdam benoemd werd tot directeur van het zoölogisch museum, dat de samengevoegde, in gebouwen van het Genootschap ondergebrachte verzamelingen van de gemeente en van het Genootschap bevatte, nadat door Burgemeester en Wethouders voornoemd deze betrekking van directeur van het zoölogisch museum was ingesteld.

Nadat door het in gebruik nemen, in 1923, van het zoölogisch laboratorium in het bovengedeelte van het gebouw De Volharding, de te voren voor het onderwijs in de zoölogie benutte ruimten in het aquariumgebouw vrijgekomen waren, werden deze ruimten door de Gemeente verbouwd en ingericht voor museumdoeleinden, waarbij o.a. belangrijke toonverzamelingen werden opgesteld. Onder deze toonverzamelingen verdient vermelding het met medewerking van de Heimans-stichting tot stand gebrachte Heimans-diorama, in het voormalige zoölogisch auditorium.

In verband met dit alles kwamen den I5den Juli 1927 wederom twee nieuwe overeenkomsten tusschen de Gemeente Amsterdam en het Genootschap tot stand, waarbij de overeenkomst van I6 Mei I892 kwam te vervallen.

Een dezer twee nieuwe overeenkomsten heeft betrekking op het verschaffen van ruimten voor en het dienstbaar maken der inrichtingen en verzamelingen van het Genootschap aan het universitaire onderwijs in de zoölogie te Amsterdam. Deze overeenkomst bracht geen wijziging in hetgeen dienaangaande in de overeenkomst van 16 Mei I892, zooals die was gewijzigd bij de overeenkomst van 8 December 1920, wend vastgelegd.

De tweede overeenkomst van 15 Juli 1927 heeft betrekking op de samenvoeging der zoölogische verzamelingen van de Gemeente en van het Genootschap. Aanleiding tot het aangaan dezer nieuwe overeenkomst was in de eerste plaats het hiervoor besproken vrijkomen der vóór I923 voor het zoölogisch 
onderwijs benutte ruimten in het aquariumgebouw en de verbouwing en inrichting dezer ruimten voor museumdoeleinden door de Gemeente, in afwachting van het weder opnemen der van 1914 dateerende, hiervoor reeds vermelde plannen tot stichting, in samenwerking tusschen de Gemeente en het Genootschap, van een groot nieuw zoölogisch museum voor de gecombineerde verzamelingen van de Gemeente en van het Genootschap.

$\mathrm{Bij}$ deze overeenkomst wend gevormd „Het Zoölogisch Museum te Amsterdam", omvattende de samengevoegde zoölogische museumverzamelingen van de Gemeente en van het Genootschap en ondergebracht in de hiervoor bedoelde ruimten in het aquariumgebouw en in de verdere museumgebouwen van het Genootschap. Daarbij wera geen uitzondering meer gemaakt voor de entomologische collectie van het Genootschap, zooals dit bij de overeenkomst van 1892 nog wel geschiedde.

Dit zoölogisch museum kwam daarbij te staan onder de leiding van een door de Gemeente bezoldigden directeur, benoemd door Burgemeester en Wethouders van Amsterdam, na ontvangst van een aanbeveling van ten minste twee personen, opgemaakt door het bestuur van het Genootschap.

Overeengekomen werd voorts, dat alle na onderteekening van deze overeenkomst in den zoölogischen tuin of in het aquarium gestorven dieren in eigendom zullen worden overgedragen aan de Gemeente voor haar museumverzamelingen of voor het universitaire onderwijs in de zoölogie.

Bepaald werd verder, dat alle museumvoorwerpen en alle kasten, vitrines en verder museummeubilair zoodanig gemerkt zullen worden, dat onmiddellijk blijken kan of zij het eigendom van de Gemeente dan wel van het Genootschap zijn, en dat alle museumvoorwerpen in een geregeld bijgehouden catalogus ingeschreven en alle kasten, vitrines en vender meubilair op lijsten gebracht zullen worden.

De Gemeente nam van het Genootschap in haar dienst over een conservator, een praeparateur en een amanuensis, waardoor de exploitatierekening van het Genootschap dan toch tenslotte ontlast werd met een jaarlijksch bedrag aan salaris en loonen, dat in $1927 f 8420$.- bedroeg.

Bovendien werden door de Gemeente aangesteld en bezoldigd: nog twee of meer conservatoren, nog een amanuensis, een bediende-stoker en één of meer suppoosten of portiers aan het zoölogisch museum in het aquariumgebouw.

Naar in deze nieuwe overeenkomst tot uitdrukking gebracht wordt, neemt de Gemeente daarbij op zich het zorgzaam beheer over de samengevoegde verzamelingen en over de musea, terwijl de rol van het Genootschap zich in hoofdzaak beperkt tot die van ingebruikgever en bewaker der verzamelingen en musea.

Ook werden regelingen getroffen betref fende ruiling, uitleening of verkoop van aan het Genootschap toebehooręnde museumvoorwerpen, alsook inzake het aandeel van elke der beide partijen in het in- en uitwendig onderhoud en het schoonhouden der diverse museumruimten en in de exploitatiekosten van het 
zoölogisch museum. Het aandeel van het Genootschap in het nadeelig saldo dezer exploitatie bedroeg in $1934 f 733,45$.

De toonverzamelingen in de museumruimten van het aquariumgebouw, in het algemeen s'echts toegankelijk voor aquariumbezoekers, werden op door den directeur. van het museum onder goedkeuring van Burgemeester en Wethouders van Amsterdam en van het bestuur van het Genootschap bepaalde en te bepalen voorwaarden bovendien af zonderlijk voor het publiek toegankelijk gesteld door den hoofdingang van het aquariumgebouw, ten minste op iederen Woensdag en iederen Zaterdag van één tot vijf uur en bovendien op zoodanige dagen en uren als de directeur van het museum in overleg met den directeur van het Genootschap zal bepalen:

Tenslotte zal het Genootschap aan de Gemeente hebben te vergoeden de door haar voor de hierboven reeds besproken verbouwing, met het oog op museumdoeleinden, van de meergeme!de ruimten in het aquariumgebouw gemakte kosten, echter tot geen hooger bedrag dan $f$ 84.000.-, wanneer:

óf het Genootschap de overeenkomst van I5 Juli 1927 opzegt, doch overigens blijft naleven de voorwaande, dat de in 1877 door de Gemeente afgestane grond zonder schriftelijke toestemming van Burgemeester en Wethouders niet anders mag worden gebezigd dan voor de oprichting en instandhouding van een aquarium of voor musea of bibliotheek op natuur-historisch gebied,

óf tengevolge van het ophouden van het gebruik als zoölogisch laboratorium van het bovengedeelte van het gebouw De Volharding de Gemeente van het Genootschap zal hebben gevorderd den kosteloozen afstand en overdracht van den door haar in 1877 aan het Genootschap afgestanen grond van het aquariumgebouw met al hetgeen daarop zal zijn gebouwd,

óf het gebruik voor het in de overeenkomst van I5 Juli 1927 aangegeven doel van de daartoe volgens die overeenkomst bestemde museumruimten feitelijk door het Genootschap wordt belet.

In 1927 werden de zeer belangrijke entomologische museumverzamelingen van het Genootschap bij de Gemeente in beheer en gebruik gegeven. Iets later werden zij zelfs gedeeltelijk buiten de terreinen van het Genootschap ondergebracht. In verband hiermede werden, naar reeds lang het plan geweest was, deze verzamelingen in 1938 door de Gemeente Amsterdam van het Genootschap overgenomen tegen de som van $f$ 32.607.-

Tenslotte werden den 28sten Augustus 1939 door het Genootschap tegen de koopsom van $f$ 1.131,000.- in eigendom overgedragen an de Provincie Noordholland (voor $1 / 4$ gedeelte) en aan de Gemeente Amsterdam (voor 3/4 gedeelte) de terreinen, tezamen groot ruim ro H.A. en 21 A., de op deze terreinen staande gebouwen, de zeer waandevolle bibliotheek en tenslotte ook de zoölogische museumverzamelingen van het Genootschap, waarbij het gekochte, met uitzondering van de perceelen en/of perceelsgedeelten, welke bij de Gemeente Amsterdam in gebruik warren, alsmede van de zich in die perceelen en/of perceelsgedeelten bevindende zoölogische museumverzamelingen, onder Bijdragen tot de Dierkunde, Afl. 28. 
door Gedeputeerde Staten van Noordholland en door Burgemeester en Wethouders van Amsterdam gezamenlijk te bepalen voorwaarden, tot wederopzeggens toe aan het Genootschap in gebruik werd gegeven, teneinde te worden aangewend voor dezelfde doeleinden, waarvoor het tot nu toe gebezigd is.

Tegen bovengenoemde koopsom kwam de Gemeente Amsterdam dan voor het eerst in het bezit van eigen gebouwen ter huisvesting van haar zoölogisch laboratorium en zoölogisch museum, welke gemeentelijke instellingen tevoren, althans sedert kort na 1877 , steeds gastvrijheid van het Genootschap hadden genoten, zonder dat.daarvoor ooit eenige verrekening had plaatsgevonden. Voor dezelfde koopsom kwam de Gemeente echter ook nog in het bezit van de terreinen, alle overige gebouwen ${ }^{2}$ ), de zoölogische museumverzamelingen en de bibliotheek van het Genootschap. Deze transactie is ongetwijfeld een voor de Gemeente Amsterdam in alle opzichten voordeelige geweest.

Het nauwe contact, dat te Amsterdam bestaat tusschen het Zoölogisch Laboratorium der Gemeente-Universiteit, het Zoölogisch Museum der Gemeente en den zoölogischen tuin van het Genootschap, welk contact uit den aard der zaak in allerlei opzichten zeer bevorderd wordt door het op één en hetzelfde terrein gelegen zijn dezer drie instellingen, is van groote ideëele waarde. Elders ter wereld wondt naar de verwezenlijking van iets dergelijks gestreefd, het ontbreken ervan als een groot gemis gevoeld.

Indien de wereld in de eerstkomende decennia voor een nieuwe catastrophe bespaard mocht blijven, zullen de hierboven vermelde, van vóór den eersten wereldoorlog dateerende plannen tot den bouw van een groot nieuw Zoölogisch Volksmuseum, dat o.a. der hoofdstad van Nederland waardige, in paedagogisch en aesthetisch opzicht zoo goed mogelijk verzorgde, voor het publiek toegankelijke toonverzamelingen zal bevatten, ongetwijfeld binnen afzienbaren tijd verwezenlijkt worden.

Er zal dan echter terdege voor gewaakt moeten worden, dat daarbij niet het contàct en speciaal ook de locale samenhang tusschen laboratorium, museum en tuin verbroken worden, m.a.w. het nieuwe museum zal op grond, grenzend aan het bij het Genootschap in gebruik zijnde terrein, gebouwd moeten worden.

Maar bovendien zal het nieuwe museumgebouw niet uitsluitend ruimte moeten bieden voor de opstelling van toonverzamelingen en voor het verrichten van zoölogische werkzaamheden op het gebied van systematiek, fau-

2) Twee dez:r' gebouwen, de voormalige concert- en tentoonstellingszaal, alsmede het gebouw met vergader- en restauratiezalen, gelegen hoek Plantage Middenlaan en Plantage Kerklaan, nam de Gemeente in 1940 zelf in gebruik ter huisvesting van de kantoren van den Burgerlijken Stand en van het Bevolkingsregister. Tot op heden heeft de ongunstige positie der bouwmaterialen het der Gemeente nog steeds onmogelijk gemaakt haar in 1940 aangegane verplichting na te komen om, ter compensatie van het in gebruik nemen van genoemde gebouwen, de voormalige koffiezaal met vestibule van het Genootschap te verbouwen en een nieuwe filmzaal en nieuwe vergaderzalen voor het Genootschap te bouwen. 
nistiek, zoögeographie en daarmede samenhangende morphologische takken van wetenschap, doch er zal daarin ook ruimschoots gelegenheid moeten zijn voor het verrichten van physiologische en vooral ook van veterinaire onderzoekingen, waartoe de zoölogische tuin geregeld zooveel belangrijk materiaal kan leveren.

Reeds vele malen kwam bij besprekingen met hoogleeraren en andere dierenartsen, verbonden aan de Veterinaire Faculteit der Rijks-Universiteit te Utrecht, tot uitdrukking van hoeveel belang het voor de veterinaire wetenschap zou zijn, indien in een daartoe ingericht laboratorium, gelegen op het terrein in gebruik bij het Genootschap, dagelijks onderzoekingen op veterinair gebied verricht zouden kunnen worden. Hiervan zou bovendien de dierenarts van het Genootschap voor de behandeling van zieke dieren en voor zijn verdere werkzaamheden betreffende de levende have van het Genootschap in hooge mate profijt kunnen trekken. De practische beteekenis van iets dergelijks zou moeilijk kunnen wonden overschat.

Wat physiologische onderzoekingen aangaat, reeds in 1928 werd door het Genootschap in een zijner gebouwen een eenvoudig doch geschikt laboratorium voor onderzoekingen op het gebied van de psycho'ogie (of ethologie) der dieren ingericht en ter beschikking gesteld van Dr. J. A. Bierens DE HaAN, toentertijd privaat-docent aan de Universiteit van Amstendam.

Behalve voor waarnemingen en onderzoekingen betreffende het gedrag der dieren (ethologie), kan van de aanwezigheid der levende have van het Genootschap echter ook in hooge mate profijt getrokken worden voor het verrichten van onderzoekingen op het gebied van andere onderdeelen der physiologie, zooals b.v. op dat der physiologie van de voedselopname, spijsvertering en stofwisseling. 